\title{
Degradation pathways of low-ethoxylated nonylphenols by isolated bacteria using an improved method
}

\author{
Yu Zhang $\cdot$ Xin Gu $\cdot$ Jing Zhang $\cdot$ Min Yang
}

Received: 8 May 2013 / Accepted: 22 July 2013 / Published online: 13 August 2013

(C) Springer-Verlag Berlin Heidelberg 2013

\begin{abstract}
Nonylphenol ethoxylates (NPEOs) with low ethoxylation degree $\left(\mathrm{NP}_{\mathrm{av} 2} \mathrm{EO}\right.$; containing two ethoxy units on average) and estrogenic properties are the intermediate products of nonionic surfactant NPEOs. To better understand the environmental fate of low-ethoxylated NPEOs, phylogenetically diverse low-ethoxylated NPEO-degrading bacteria were isolated from activated sludge using gellan gum as the gelling reagent. Four isolates belonging to four genera, i.e., Pseudomonas sp. $\mathrm{NP522b}$ in $\gamma$-Proteobacteria, Variovorax sp. NP427b and Ralstonia sp. NP47a in $\beta$-Proteobacteria, and Sphingomonas sp. NP42a in $\alpha$-Proteobacteria were acquired. Ralstonia sp. NP47a or Sphingomonas sp. NP42a, have not been reported for the degradation of low-ethoxylated NPEOs previously. The biotransformation pathways of these isolates were investigated. The first three strains (NP522b, NP427b, and NP47a) exhibited high $\mathrm{NP}_{\mathrm{av} 2} \mathrm{EO}$ oxidation ability by oxidizing the polyethoxy (EO) chain to form low-ethoxylated nonylphenoxy carboxylates, and then further oxidizing the alkyl chain to form carboxyalkylphenol polyethoxycarboxylates. Furthermore, Sphingomonas sp. NP42a degraded $\mathrm{NP}_{\mathrm{av} 2}$ EO through a nonoxidative pathway with nonylphenol monoethoxylate as the dominant product.
\end{abstract}

Keywords Low-ethoxylated nonylphenol ethoxylates · Degrading bacteria $\cdot$ Biodegradation pathway $\cdot$ Gelling reagent

Responsible editor: Robert Duran

Electronic supplementary material The online version of this article (doi:10.1007/s11356-013-2038-6) contains supplementary material, which is available to authorized users.

Y. Zhang $\cdot \mathrm{X} . \mathrm{Gu} \cdot \mathrm{J}$. Zhang $\cdot$ M. Yang $(\triangle)$

State Key Laboratory of Environmental Aquatic Chemistry,

Research Center for Eco-Environmental Sciences, Chinese Academy

of Sciences, P.O. Box 2871, Beijing 100085, China

e-mail: yangmin@rcees.ac.cn

\section{Introduction}

Nonylphenol ethoxylates (NPEOs), which consist of a polyethoxy chain (EO chain, commonly containing nine ethoxy units) and a branched alkyl chain (C9) connected to a benzene ring (Fig. 1), are a major class of nonionic surfactants used in household, industrial, and agricultural applications (Bergé et al. 2012a,b). Although the production of NPEOs has exhibited a decreasing trend in the USA, Canada, and the EU as a result of highly restrictive regulations (EU 2003; USEPA 2010), worldwide output increased from $300,000 \mathrm{t}$ in 1994 to $500,000 \mathrm{t}$ in 2002 (Berryman et al. 2003; Ying et al. 2002). The increase in consumption by emerging nations such as Brazil, Russia, India, and China has been considered as the main reason (Bergé et al. 2012a).

NPEOs are incompletely degraded to low-ethoxylated NPEOs (containing one to three ethoxy units), nonylphenoxy carboxylates (NPECs), nonylphenol (NP), and carboxyalkylphenol polyethoxycarboxylates (CAPECs) in wastewater treatment plants (WWTPs) and water environments (Ahel et al. 1994; Bergé et al. 2012a,b; Di Corcia et al. 2000; Gonzalez et al. 2007; He et al. 2013; Koh et al. 2008; Maguire 1999; Montgomery-Brown and Reinhard 2003; Nagarnaik et al. 2010; Xu et al. 2011). Bergé et al. (2012a) found that total concentrations of NPEO and their metabolites (mainly low-ethoxylated NPEOs and low-ethoxylated NPECs) were $0.10-1,179 \mu \mathrm{g} \mathrm{L}^{-1}$ (mean, $4.54 \mu \mathrm{g} \mathrm{L}^{-1}$ ) in WWTP effluent and 0.03-215 $\mu \mathrm{g} \mathrm{L}^{-1}\left(0.99 \mu \mathrm{g} \mathrm{L}^{-1}\right)$ in surface water. Some biodegradation intermediates, such as NP and low-ethoxylated NPEOs $\left(\mathrm{NP}_{1-3} \mathrm{EO}\right)$, exhibit estrogenic properties, and therefore, the biotransformation pathways of NPEOs have been widely studied using isolated bacteria (John and White 1998; Liu et al. 2006, 2013; Lu et al. 2008; Sato et al. 2001, 2003; Ying et al. 2002). It is generally accepted that at least two EO chain degradation pathways lead to the 


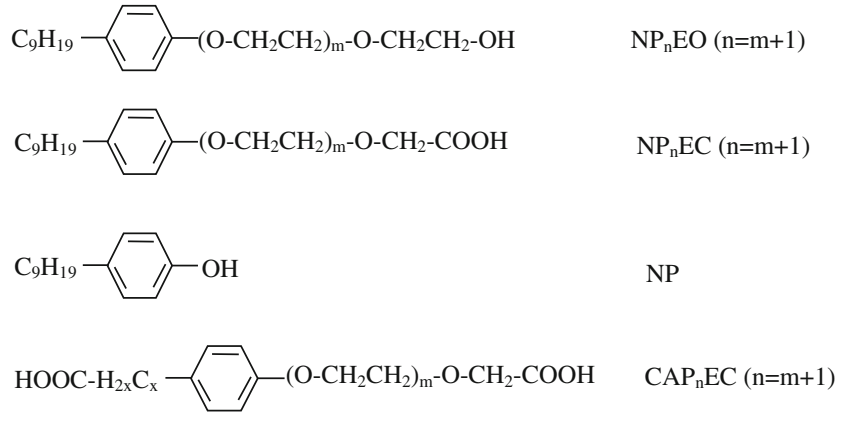

Fig. 1 General structures and acronyms of NPEOs and their wellascertained degradation intermediates

production of metabolites with shortened ethoxy chains (lowethoxylated NPEOs) and carboxylated ethoxy chains (lowethoxylated NPECs).

Since low-ethoxylated NPEOs exhibit estrogenic properties (Jobling et al. 1996; Routledge and Sumpter 1996), the final fates of low-ethoxylated NPEOs using isolated bacteria have also been studied. Isolates belonging to the genera Stenotrophomonas, Pseudomonas, Ochrobactrum, Castellaniella, Variovorax, and Psychrobacter degrade $\mathrm{NP}_{\text {av1.5 }}$ EOs (containing 1.5 ethoxy units on average) and $\mathrm{NP}_{\mathrm{av} 5.0} \mathrm{EOs}$ (containing 5.0 ethoxy units on average), while their biotransformation pathways and metabolites remain unclear (Di Gioia et al. 2008; Salvadori et al. 2006). Liu et al. (2006) isolated two strains (Ensifer sp. and Pseudomonas sp.) capable of transforming nonylphenol diethoxylate $\left(\mathrm{NP}_{2} \mathrm{EO}\right)$ to nonylphenol monoethoxylate $\left(\mathrm{NP}_{1} \mathrm{EO}\right)$. In comparison with their mother molecules, however, information regarding the fates of low-ethoxylated NPEOs is still very limited. It is not clear, for example, why low-ethoxylated CAPECs, the metabolites with oxidized alkyl and ethoxy side chains, accumulate in the environment as a result of NPEO biotransformation (Ahel et al. 1994; Di Corcia et al. 1998; Jonkers et al. 2001; Montgomery-Brown et al. 2003, 2008).

It is known that isolated bacteria acquired through conventional isolation methods cannot represent the actual distribution of NPEO-degrading bacteria in the environment, and may not be able to reveal the actual biotransformation pathway (Lozada et al. 2004, 2006; Zhang et al. 2008a). Recently, we found two novel high-ethoxylated NPEO $\left(\mathrm{NP}_{\mathrm{av}} \mathrm{EO}\right)$ pathways based on phylogenetically diverse $\mathrm{NP}_{\mathrm{av} 9}$ EOs-degrading isolates acquired using gellan gum as the gelling reagent $(\mathrm{Gu}$ et al. 2010). Therefore, it may be possible to acquire phylogenetically diverse low-ethoxylated NPEO-degrading isolates based on the same cultivation strategy. Using this improved method, we isolated novel low-ethoxylated NPEO $\left(\mathrm{NP}_{\mathrm{av} 2} \mathrm{EO}\right)$-degrading bacteria from activated sludge and used the isolates to study the biotransformation pathways of $\mathrm{NP}_{\mathrm{av} 2} \mathrm{EO}$. This study will help understand the fates of NPEOs in WWTPs and related environments.

\section{Materials and methods}

Reagents and chemicals

Technical grade NPEO surfactant mixtures with an ethoxylate range of $1-4$ and an average $\mathrm{EO}$ chain length of $2\left(\mathrm{NP}_{\mathrm{av} 2} \mathrm{EO}\right)$ were obtained from Tokyo Chemical Industry Co., Ltd. (Tokyo, Japan), as a mixture of $\mathrm{NP}_{1} \mathrm{EO}(32.6 \%), \mathrm{NP}_{2} \mathrm{EO}$ (39.0 \%), $\mathrm{NP}_{3} \mathrm{EO}(16.2 \%), \mathrm{NP}_{4} \mathrm{EO}(5.3 \%)$, and some impurities (6.9\%). Nonylphenol (NP) with a linear alkyl chain (4$\mathrm{n}$-NP) was used as an internal standard for gas chromatography-mass spectrometry (GC-MS) analysis and was purchased from Fluka (Seinheim, Germany). Mixed NPEC standards with EO chain lengths ranging from 0 to 9 corresponding to $\mathrm{NP}_{1} \mathrm{EC}$ up to $\mathrm{NP}_{10} \mathrm{EC}$, and $\mathrm{NP}$ were obtained from Hayashi Pure Chemicals (Osaka, Japan). We obtained N,O-bis (trimethylsilyl)trifluoroacetamide (BSTFA) containing $1 \%$ trimethyl-chlorosilane, which was used for trimethylsilylation, as well as gellan gum and agar used as gelling reagents from Supelco (Bellefonte, PA, USA). Methanol, dichloromethane, $n$-hexane, and acetonitrile [high-performance liquid chromatography (HPLC) grade] were obtained from the Fisher Company (Muskegon, MI, USA). Ammonium acetate of HPLC grade was purchased from Fluka (Steinheim, Germany). All water (18.2 M $\Omega$ ) used in this study was purified using PURICMXII apparatus (Organo, Japan). General structures and acronyms of NPEOs and their well-ascertained intermediates are presented in Fig. 1.

Screening and identification of low-ethoxylated NPEO-degrading bacteria

A sludge sample was collected from an activated sludge reactor used to treat NPEO-containing wastewater (Zhang et al. 2008b) and inoculated into modified PE03 medium containing $\mathrm{NP}_{\mathrm{av} 2} \mathrm{EO}\left(500 \mathrm{mg} \mathrm{L}^{-1}\right)$ as the only carbon source. The $\mathrm{NP}_{\mathrm{av} 2} \mathrm{EO}$ were firstly dissolved in hexane, evaporated to dryness, and then redissolved in medium with a final concentration of $500 \mathrm{mg} \mathrm{L}^{-1}$. The modified PE03 medium contained $0.38 \mathrm{~g} / \mathrm{L}$ of $\mathrm{KH}_{2} \mathrm{PO}_{4}, 0.39 \mathrm{~g} / \mathrm{L}$ of $\mathrm{K}_{2} \mathrm{HPO}_{4}, 0.5 \mathrm{~g} / \mathrm{L}$ of $\left(\mathrm{NH}_{4}\right)_{2} \mathrm{SO}_{4}, 5 \mathrm{~mL}$ of basal salts solution, and $1 \mathrm{~mL}$ of vitamin solution per liter (Hanada et al. 1995). The cultures were then incubated aerobically at $30{ }^{\circ} \mathrm{C}$ with shaking at $140 \mathrm{rpm}$. The enrichment cycles were repeated at 10-day intervals for 6 months (Salvadori et al. 2006). Finally, $100 \mu \mathrm{L}$ of appropriately diluted culture broth was spread on PE03-NP ${ }_{\mathrm{av} 2} \mathrm{EO}$ (50 $\mathrm{mg} \mathrm{L}^{-1}$ ) gellan gum or agar plates and then incubated at $30^{\circ} \mathrm{C}$ in the dark for 2 days. We isolated 130 randomly chosen colonies for each sampling time and then screened them for their ability to grow in the presence of $\mathrm{NP}_{\mathrm{av} 2} \mathrm{EO}$. Next, seven restriction types using AluI were selected. Seven morphologically distinct colonies from the seven restriction types, which could grow in the presence of $\mathrm{NP}_{\mathrm{av} 2} \mathrm{EO}$ on gellan gum or agar 
plates, were further identified by amplification of their $16 \mathrm{~S}$ rRNA genes using universal bacterial primers $27 \mathrm{~F}$ and $1492 \mathrm{R}$ (Lane 1991). The PCR products were subjected to electrophoresis on $1.2 \%$ agarose gels, stained with ethidium bromide $\left(0.5 \mu \mathrm{g} \mathrm{mL}^{-1}\right)$ and visualized by UV excitation. Furthermore, the PCR products were purified using a QIAquick PCR purification kit (QIAGEN, Japan) according to the manufacturer's protocols, and were then digested for $5 \mathrm{~h}$ at $37^{\circ} \mathrm{C}$ with $\mathrm{AluI}$. The seven morphologically distinct colonies from the seven restriction types were selected, purified, and tested for their ability to degrade $\mathrm{NP}_{\mathrm{av} 2} \mathrm{EO}$. The nucleotide sequences of the $16 \mathrm{~S}$ rRNA genes obtained were then submitted to GenBank and assigned the following accession numbers: NP47a (EU580702), NP42a (EU580703), NP428a (EU580704), NP427b (EU580705), NP522b (EU723211), NP631a (EU723212), and NP526a (EU723213). Strains named with "a" were acquired on the gellan gum-based media, while those named with "b" could be obtained on both media.

Biodegradation of $\mathrm{NP}_{\mathrm{av} 2} \mathrm{EO}$ using isolated bacteria

All isolates were previously grown to the log phase in LuriaBertani liquid medium supplemented with $\mathrm{NP}_{\mathrm{av} 2} \mathrm{EO}$. A $100-\mu \mathrm{L}$ aliquot of the culture medium, with optical density at $600 \mathrm{~nm}$ adjusted to 0.5 , was then used to inoculate $250-\mathrm{mL}$ Erlenmeyer flasks containing $100 \mathrm{~mL}$ of PE03-NP $\mathrm{av}_{2} \mathrm{EO}$ medium. The samples were then subjected to constant shaking at $140 \mathrm{rpm}$ and $30^{\circ} \mathrm{C}$ for 20 days, and growth was evaluated by measuring the optical density at $600 \mathrm{~nm}$ using a spectrophotometer (Hitachi, UV3010). All assays were conducted in duplicate, and test blanks were added to measure abiotic losses.

After a designated time, the culture medium $(2 \mathrm{~mL})$ was collected from the flasks, stabilized with $20 \mu \mathrm{L}$ of formaldehyde, and acidified to $\mathrm{pH} 2$ with $\mathrm{HCl}$. The medium was then extracted using an equal volume of ethyl acetate/methanol (7:3, $v / v)$ twice by shaking the mixture vigorously. The collected organic phases were then blown dry under a gentle flow of nitrogen. For liquid chromatography-mass spectrometry (LCMS) and GC-MS analyses, dried samples were redissolved in $1 \mathrm{~mL}$ of methanol/pure water $1: 1(\mathrm{v} / \mathrm{v})$ and $0.4 \mathrm{~mL}$ of $n$-hexane hexyl hydride, respectively.

Analytical methods

Low-ethoxylated NPEOs were analyzed using a gas chromatograph (GC) (Agilent Technologies, 6890 GC) interfaced with a DB-5MS capillary column $(30 \mathrm{~m} \times 0.25 \mathrm{~mm} \times 0.25 \mu \mathrm{m})$ and a mass spectrometer (MS) (Agilent Technologies, 5975i MSD) (Isobe et al. 2001). Briefly, the dried samples were redissolved in $n$-hexane, derivatized with BSTFA and then subjected to GC-MS analysis. The GC column temperature was programmed to increase from $50{ }^{\circ} \mathrm{C}$ (initial equilibrium time, $2 \mathrm{~min}$ ) to $200^{\circ} \mathrm{C}$ via a ramp of $20^{\circ} \mathrm{C} \mathrm{min}^{-1}$, from 200 to $260{ }^{\circ} \mathrm{C}$ via a ramp of $5^{\circ} \mathrm{C} \mathrm{min}^{-1}$, and from 260 to $280{ }^{\circ} \mathrm{C}$ via a ramp of $20{ }^{\circ} \mathrm{C} \mathrm{min}{ }^{-1}$, after which the temperature was maintained at $280{ }^{\circ} \mathrm{C}$ for 2 min. Helium carrier gas was maintained at a constant flow rate of $1 \mathrm{~mL} \mathrm{~min}^{-1}$. Compounds were identified by comparison with previously published results (Isobe et al. 2001) and quantified in selective ion monitoring mode.

Analysis of NPECs was conducted using a Waters LC-MS system (Alliance 2690 HPLC system linked to a Micromass ZQ 4000) equipped with a Waters Symmetry Shield ${ }^{\mathrm{TM}}$ RP18 column $(150 \times 2.1 \mathrm{~mm}, 3.5 \mu \mathrm{m})$ (Zhang et al. 2007). The mobile phase was a mixture of $5 \mathrm{mmol} \mathrm{L}^{-1}$ ammonium acetate solution (A) and pure methanol (B). Gradient elution was performed as follows: $30 \%$ methanol held for $5 \mathrm{~min}$, linearly increased to $85 \%$ in $7 \mathrm{~min}$ and held for $9 \mathrm{~min}$, and then increased to $97 \%$ and held for $5 \mathrm{~min}$, and finally brought back to $30 \%$ and held for 8 min until the next injection. The flow rate was $0.2 \mathrm{~mL} \mathrm{~min}^{-1}$. The column oven was maintained at $35^{\circ} \mathrm{C}$, and the injection volume was $10 \mu \mathrm{L}$. All analyses were performed in the selected ion recording mode using the deprotonated molecular ions of NPECs during negative ionization. The method recovery obtained after stabilization, acidification, and extraction of culture medium spiked with lowethoxylated NPEOs and NPECs ranged from $93 \pm 10 \%$ to $102 \pm 3.0 \%$ and $75 \pm 4.5 \%$ to $98 \pm 12 \%$, respectively. Relative standard deviation was below $12 \%$. Instrumental limits of detection and linear range were $25 \mathrm{pg}$ and $2.5-500 \mu \mathrm{g} \mathrm{L}^{-1}$ for $\mathrm{NP}_{1-10} \mathrm{EC}$, respectively. Detailed information on the analytical methods is shown in Table S1 (see supplementary data).

Carboxyalkylphenol polyethoxycarboxylates were investigated as per Di Corcia et al. (2000) and Jonkers et al. (2001). Quantification of CAPEC was made more difficult because of the lack of any standard, which may have introduced some inaccuracy. For identity confirmation of CAPECs, LC-ESMS/MS was used mass spectrometry was carried out on a Waters Quattro Premier XE tandem quadrupole mass spectrometer (Waters Corp., Manchester, UK) using negative electrospray ionization (ESI). The range of $\mathrm{m} / \mathrm{z}$, scan period, and scan delay time were 50-500 amu, $0.5 \mathrm{~s}$, and $0.1 \mathrm{~s}$, respectively. The source and desolvation temperatures were held at 120 and $400{ }^{\circ} \mathrm{C}$, respectively. Desolvation gas and cone gas were set at flow rates of 600 and $60 \mathrm{~L} / \mathrm{h}$, respectively.

\section{Results and discussion}

Taxonomic characteristics and $\mathrm{NP}_{\mathrm{av} 2} \mathrm{EO}$ degradation capability

Using the improved method, seven isolates grown in the presence of $\mathrm{NP}_{\mathrm{av} 2} \mathrm{EO}$ were acquired and labeled as strains NP42a, NP47a, NP428a, NP427b, NP526a, NP631a, and 
NP522b, the 16S rRNA gene sequences of which were $>99 \%$ homologous with Sphingomonas chungbukensis (AF159257), Ralstonia eutropha (EU827495), Alicycliphilus denitrificans (NR_074585), Variovorax paradoxus (AF532868), Shinella zooloeoides (EU346730), Achromobacter insolitus (NR_025685), and Pseudomonas aeruginosa (GQ926936), respectively. As shown in Fig. 2, these strains were distributed widely in $\alpha, \beta$ and $\gamma$ classes of Proteobacteria phylum and could be assigned to seven different genera: Sphingomonas sp. NP42a, Ralstonia sp. NP47a, Alicycliphilus sp. NP428a, Variovorax sp. NP427b, Pseudomonas sp. NP522b, Shinella sp. NP526a, and Achromobacter sp. NP631a. While all seven strains were acquired on the gellan gum-based media, only two strains (NP522b and NP427b) were obtained on the agar based media, showing gellan gum led to the isolation of phylogenetically diverse strains.

Among the seven isolates, NP522b (Pseudomonas), NP427b (Variovorax), NP47a (Ralstonia), and NP42a (Sphingomonas) were found to grow in PE03-NP ${ }_{\mathrm{av} 2} \mathrm{EO}$ medium rapidly within two days and had the ability to degrade $\mathrm{NP}_{\mathrm{av} 2} \mathrm{EO}$. The degradation ratios of $\mathrm{NP}_{\mathrm{av} 2} \mathrm{EO}$ and the main products detected in the above four degradation systems are listed in Table $\mathrm{S} 2$ (see supplementary data). No $\mathrm{NP}_{\mathrm{av} 2} \mathrm{EO}$ losses were found in the test blanks without strains. Both NP42a (Sphingomonas) and NP427b (Variovorax) were closely related to previously reported low-ethoxylated NPEOs-degrading bacteria (Di Gioia et al. 2008); however, no members from the latter two genera (NP47a (Ralstonia) and NP42a (Sphingomonas) have been previously identified as low-ethoxylated NPEO degraders.

Biotransformation pathways of $\mathrm{NP}_{\mathrm{av} 2} \mathrm{EO}$ by isolated bacteria

Low-ethoxylated NPEOs are recalcitrant intermediate products of nonionic surfactant NPEOs. In comparison with their mother molecules, information regarding the fates of lowethoxylated NPEOs is very limited. Liu et al. (2006, 2007) isolated two strains (Ensifer sp. and Pseudomonas sp.) capable of aerobically degrading low-ethoxylated NPEOs. As shown in Fig. 3a, shorter NPEOs and NPECs were formed through stepwise oxidation of the terminal alcohol group of the EO chain with the final degradation product as NP. We proposed two new pathways as shown in Fig. $3 \mathrm{~b}$ and c.

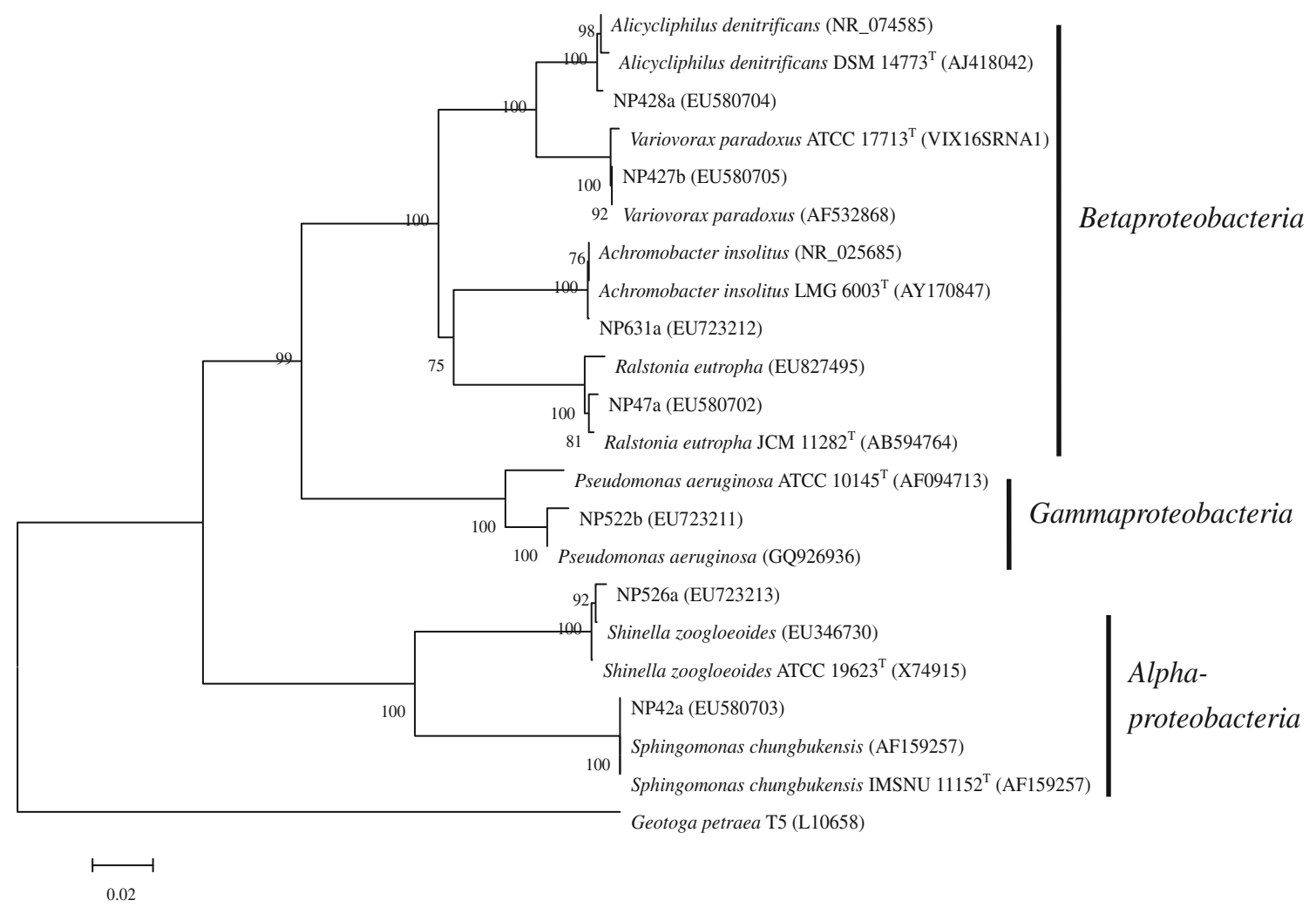

Fig. 2 Phylogenetic affiliation of isolated strains NP42a, NP47a, NP428a, NP427b, NP526a, NP631a, and NP522b based on nucleotide sequences of the 16S rRNA genes. The phylogenetic tree was constructed using neighbor-joining algorithm with the Jukes-Cantor distance in the PHYLIP software (http://evolution.genetics.washington.edu/phylip. $\mathrm{html}$ ). The 16S rRNA gene sequence of Geotoga petraea (belonging to the Phylum Thermotogae) was selected as the outgroup. Reference sequences and type strain sequences were obtained from the Ribosomal Database Project database (http://rdp.cme.msu.edu/) and StrainInfo (http://www.straininfo.net/), respectively. GenBank accession numbers are shown in parentheses 


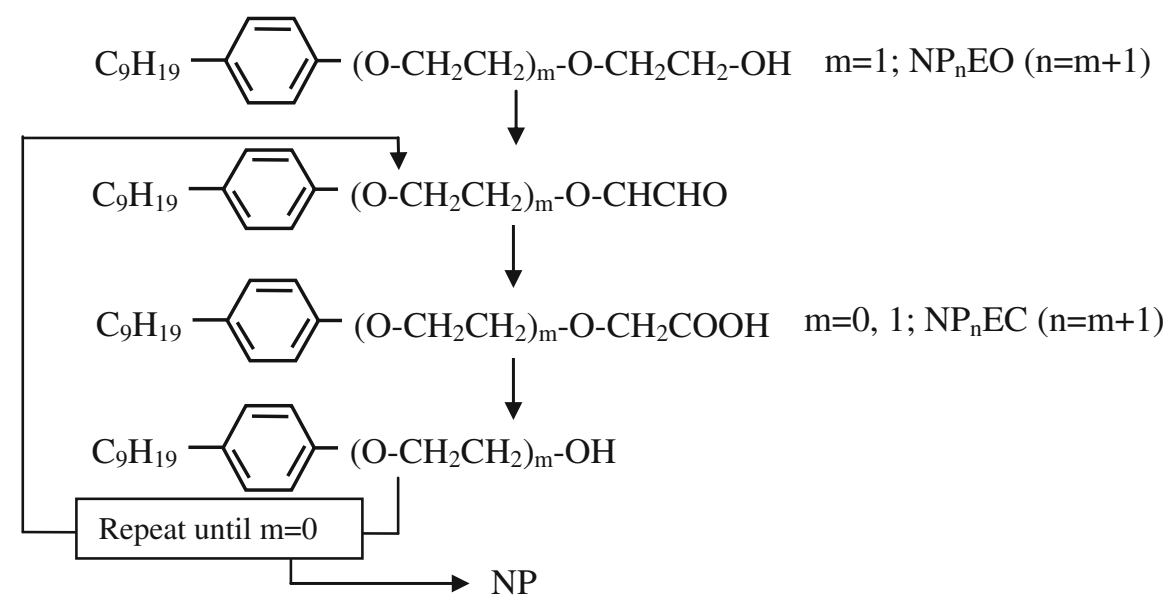

(a) Reported pathway: formation of $\mathrm{NP}_{1} \mathrm{EO}, \mathrm{NP}_{1} \mathrm{EC}$, and $\mathrm{NP}$ by Ensifer sp. and Pseudomonas sp. (Liu et al. 2006, 2007)

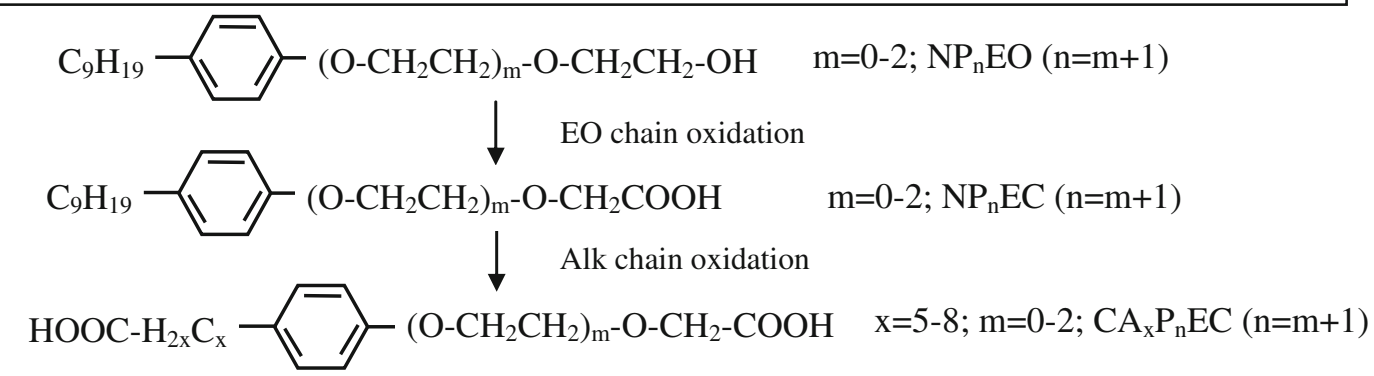

(b) Pathway 1 in the present study: Direct oxidation of $\mathrm{NP}_{\mathrm{av} 2} \mathrm{EO}$, and formation of NPECs and CAPEC by Variovorax sp. NP427b, Ralstonia sp. NP47a, and Pseudomonas sp. NP522b.

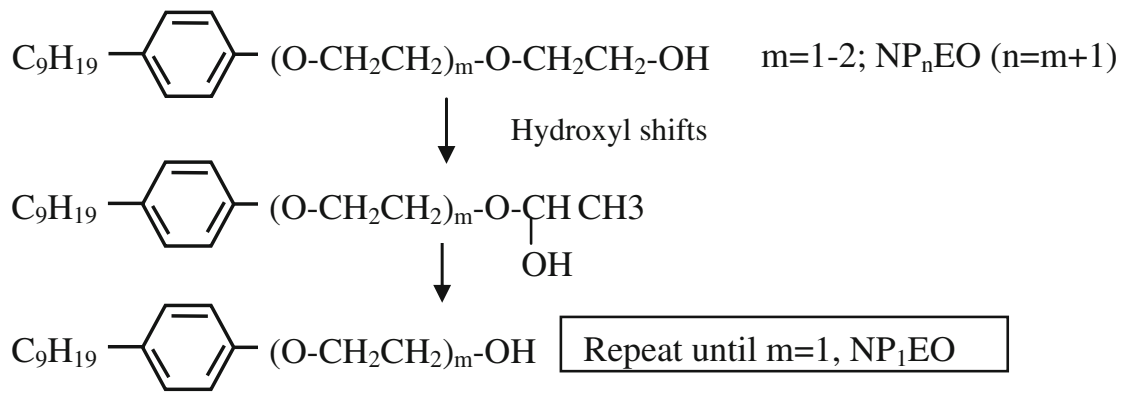

(c) Pathway 2 in the present study: Hydroxyl shift cleavage of $\mathrm{NP}_{\text {av } 2} \mathrm{EO}$ with $\mathrm{NP}_{1} \mathrm{EO}$ as the major degradation products by Sphingomonas sp. NP42a.

Fig. 3 Biodegradation pathways of low-ethoxylated NPEOs proposed by a Liu et al. $(2006,2007)$, b direct oxidation of $\mathrm{NP}_{\mathrm{av} 2} \mathrm{EO}$, and $\mathbf{c}$ Hydroxyl shift cleavage of $\mathrm{NP}_{\mathrm{av} 2} \mathrm{EO}$ based on the results of this study

Pathway 1: direct oxidation of $\mathrm{NP}_{\mathrm{av} 2} \mathrm{EO}$ with NPECs and CAPECs as the major degradation products by Ralstonia sp. NP47a, Variovorax sp. NP427b, and Pseudomonas sp. NP522b

Strains Ralstonia sp. NP47a, Variovorax sp. NP427b, and Pseudomonas sp. NP522b were capable of degrading 53.6, 28.1 , and $26.5 \%$ (molar percentage) of $\mathrm{NP}_{\mathrm{av} 2} \mathrm{EO}$ on day 10 , respectively (Table $\mathrm{S} 2$ in supplementary data). The proportion of residual $\mathrm{NP}_{1} \mathrm{EO}, \mathrm{NP}_{2} \mathrm{EO}$, and $\mathrm{NP}_{3} \mathrm{EO}$ in the mixture did not change over the duration of the experiment in comparison with the original $\mathrm{NP}_{\mathrm{av} 2} \mathrm{EO}$. At the same time, a considerable amount of NPECs $(n=1-3)$ were detected in all culture systems. Figure $4 \mathrm{a}$ and $\mathrm{b}$ shows that the cell density of strain $\mathrm{NP} 47$ a (indicated by changes in $\mathrm{OD}_{600}$ ) and the concentrations of three NPEC species increased with decreasing concentration of $\mathrm{NP}_{\mathrm{av} 2} \mathrm{EO}$ over a period of 10 days. In our previous study, a strain having the same morphological traits and $16 \mathrm{~S}$ rRNA gene sequence as NP47a transformed $\mathrm{NP}_{11} \mathrm{EO}$ to its corresponding carboxylated products $\left(\mathrm{NP}_{11} \mathrm{EC}\right)$ at much 
(a)

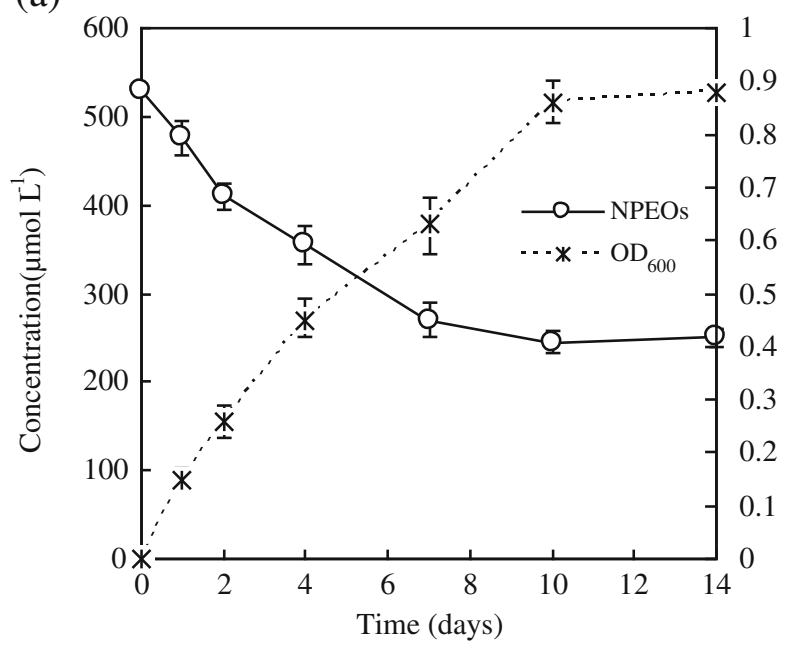

(b)

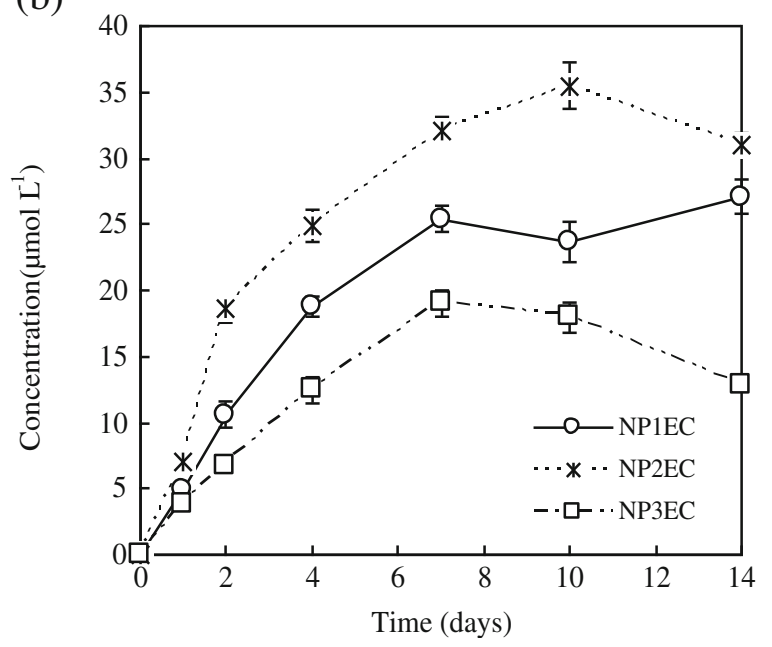

Fig. 4 Utilization of $\mathrm{NP}_{\mathrm{av} 2} \mathrm{EO}$ as a growth substrate for strain NP47a. a Growth was assessed based on optical density at $600 \mathrm{~nm}$ (OD600). Residual amounts of NPEOs (EO chain length $n<3$ ) were determined by GC-MS analysis of organic extracts of the entire culture medium. $\mathbf{b}$ Changes in concentration of NPECs $(n=1-3)$ in the culture media during incubation of strain NP47a

lower degradation and bacterial growth rates (Gu et al. 2010). Thus, low-ethoxylated NPEOs appeared more suitable carbon sources for the growth of NP47a. Formation of CAPECs was confirmed on day 10. Mass balances at different sampling times for strain NP47a are summarized in Table 1. The residual NPEOs and the three NPEC and seven CAPEC metabolites accounted for approximately $46.4,14.6$, and $19.0 \%$ of the initial $\mathrm{NP}_{\mathrm{av} 2} \mathrm{EO}$ molar concentration on day 10 , respectively (Table 1). The incomplete extraction from bacterial cells and the existence of some undetected metabolites might be responsible for the missing mass.

The total ion chromatogram of LC-MS for the degradation sample taken on day 10 showed that besides the co-elution peak of NPECs at $14.2 \mathrm{~min}$, two new peaks were found at 12.8 and $13.1 \mathrm{~min}$ (supplementary data Fig. S1). Since they show
Table 1 Mass balances at different sampling times for $\mathrm{NP}_{\mathrm{av} 2} \mathrm{EO}$ degradation using strain NP47a

\begin{tabular}{|c|c|c|c|c|c|c|}
\hline \multirow[t]{2}{*}{$\begin{array}{l}\text { Sampling } \\
\text { time } \\
\text { (day) }\end{array}$} & \multirow{2}{*}{$\begin{array}{l}\text { Molar } \\
\text { percentage } \\
\text { of detected } \\
\text { residual } \\
\mathrm{NP}_{\text {av2 } 2} \mathrm{EO} \text { to } \\
\text { initial } \\
\mathrm{NP}_{\text {av2 } 2} \mathrm{EO} \\
(\%)\end{array}$} & \multicolumn{4}{|c|}{$\begin{array}{l}\text { Molar percentage of detected } \\
\text { NPECs }(n=1-3) \text { to initial } \\
\mathrm{NP}_{\mathrm{av} 2} \mathrm{EO}(\%)\end{array}$} & \multirow{2}{*}{$\begin{array}{l}\text { Molar } \\
\text { percentage } \\
\text { of detected } \\
\text { CAPECs to } \\
\text { initial } \\
\mathrm{NP}_{\mathrm{av} 2} \mathrm{EO} \\
(\%) \\
\text { Total }\end{array}$} \\
\hline & & $\mathrm{NP}_{1} \mathrm{EC}$ & $\mathrm{NP}_{2} \mathrm{EC}$ & $\mathrm{NP}_{3} \mathrm{EC}$ & Total & \\
\hline 0 & 100 & 0 & 0 & 0 & 0 & - \\
\hline 1 & 90.1 & 0.92 & 1.32 & 0.72 & 2.96 & - \\
\hline 2 & 77.7 & 2.00 & 3.52 & 1.28 & 6.79 & - \\
\hline 4 & 67.4 & 3.56 & 4.72 & 2.36 & 10.6 & - \\
\hline 7 & 50.9 & 4.80 & 6.07 & 3.60 & 14.5 & - \\
\hline 10 & 46.4 & 4.48 & 6.71 & 3.40 & 14.6 & 19.03 \\
\hline
\end{tabular}

$[\mathrm{M}-\mathrm{H}]^{-}$ions in the negative mode with $\mathrm{m} / \mathrm{z}$ values of 309 and 351 , respectively, the related molecular weights were 310 and 352 , which might be assigned to $\mathrm{CA}_{5} \mathrm{P}_{2} \mathrm{EC}$ and $\mathrm{CA}_{8} \mathrm{P}_{2} \mathrm{EC}$, respectively (Jonkers et al. 2001). We employed LC-ESI-MS/ MS to further confirm this speculation as shown in Fig. S2a (see supplementary data). For $\mathrm{m} / \mathrm{z} 309$ at the collision voltage of $20 \mathrm{~V}$, the fragment $\mathrm{m} / \mathrm{z}$ was 163 , which might be attributed to $\left[\mathrm{CH}_{3}-\mathrm{C}_{4} \mathrm{H}_{8}-\mathrm{C}_{6} \mathrm{H}_{4}-\mathrm{O}\right]^{-}$due to the loss of $\mathrm{COO}-$ group and EO chain cleavage from $\mathrm{CA}_{5} \mathrm{P}_{2} \mathrm{EC}$. Similarly, since there were mass differences in the three methylene groups $(m / z=42)$ between $\mathrm{CA}_{8} \mathrm{P}_{2} \mathrm{EC}$ and $\mathrm{CA}_{5} \mathrm{P}_{2} \mathrm{EC}$, the fragment of $\mathrm{m} / z 351$ was $m / z 205$ (see supplementary data Fig. S2b).

Using the above approach, the other unknown compounds were also assigned as CAPEC metabolites, including $\mathrm{CA}_{7} \mathrm{P}_{2} \mathrm{EC}(\mathrm{m} / z=337), \mathrm{CA}_{8} \mathrm{P}_{1} \mathrm{EC}(m / z=307), \mathrm{CA}_{6} \mathrm{P}_{1} \mathrm{EC}(\mathrm{m} /$ $z=279), \mathrm{CA}_{5} \mathrm{P}_{1} \mathrm{EC}(\mathrm{m} / z=265)$, and $\mathrm{CA}_{5} \mathrm{P}_{3} \mathrm{EC}(\mathrm{m} / z=353)$. As standards of most CAPECs were unavailable, their quantification was performed by assuming that CAPECs had the same molar response factors as the corresponding NPECs (Jonkers et al. 2001). The semiquantitative results of CAPECs formed by strains NP47a, NP427b, and NP522b were calculated as shown in Table 2. The total CAPEC concentrations formed on day 10 were $100.6,48.7$, and $24.3 \mu \mathrm{M}$ for NP47a, NP427b, and NP522b, respectively. The length of the alkyl chain and EO chain were 5-8 $\left(\mathrm{CA}_{5} \mathrm{EC}-\mathrm{CA}_{8} \mathrm{EC}\right)$ and $1-3\left(\mathrm{CAP}_{1} \mathrm{EC}-\right.$ $\mathrm{CAP}_{3} \mathrm{EC}$ ), respectively. No products with shorter alkyl chains were found. The highly branched nature of the alkyl chain might have limited the rate and extent of its further oxidation (Montgomery-Brown et al. 2003). Both $\mathrm{CA}_{8} \mathrm{PEC}$ and $\mathrm{CA}_{5} \mathrm{PEC}$ were the most abundant CAPEC formation species, which was in accordance with previous laboratory-scale bioreactor findings (Jonkers et al. 2001). Researchers have postulated that $\mathrm{CA}_{8} \mathrm{PECs}$ and $\mathrm{CA}_{5} \mathrm{PECs}$ may result from the $\omega / \beta$ oxidation of certain NPECs (Montgomery-Brown and Reinhard 2003). 
Table 2 Formation of CAPECs $(\mu \mathrm{M})$ by low-ethoxylated NPEO-degrading isolates on day 10

\begin{tabular}{lllllllll}
\hline Strain & $\mathrm{CA}_{5} \mathrm{P}_{1} \mathrm{EC}$ & $\mathrm{CA}_{5} \mathrm{P}_{2} \mathrm{EC}$ & $\mathrm{CA}_{5} \mathrm{P}_{3} \mathrm{EC}$ & $\mathrm{CA}_{6} \mathrm{P}_{1} \mathrm{EC}$ & $\mathrm{CA}_{7} \mathrm{P}_{2} \mathrm{EC}$ & $\mathrm{CA}_{8} \mathrm{P}_{1} \mathrm{EC}$ & $\mathrm{CA}_{8} \mathrm{P}_{2} \mathrm{EC}$ & $\mathrm{T}$ \\
\hline NP47a & 14.12 & 25.67 & 6.89 & 2.60 & 3.52 & 5.55 & 42.27 \\
NP427b & 9.50 & 19.41 & 7.94 & 1.16 & 0.71 & 2.71 & 7.26 \\
NP522b & 4.15 & 10.09 & 1.69 & 0.55 & 1.02 & 0.73 & 5.94 \\
\hline
\end{tabular}

As shown in Table 2, CAPECs were detected in all three $\mathrm{NP}_{\mathrm{av} 2} \mathrm{EO}$ degradation systems on day 10 , showing that NP47a, NP427b, and NP522b had high oxidation power to degrade the alkyl group. Since the first detection of CAPECs $\left(\mathrm{CAP}_{1} \mathrm{EC}\right.$ and $\left.\mathrm{CAP}_{2} \mathrm{EC}\right)$ from tertiary treated effluent (Ding et al. 1996), many laboratory and field studies have shown that CAPECs are the main metabolites of NPEOs (Di Corcia et al. 1998; Jonkers et al. 2001; Montgomery-Brown et al. 2003, 2008). Di Corcia et al. (1998) found that $\mathrm{CA}_{3-8} \mathrm{P}_{1} \mathrm{ECs}$ and $\mathrm{CA}_{3-8} \mathrm{P}_{2} \mathrm{ECs}$ appeared as the main and extremely persistent intermediates in an OECD biodegradation test of $\mathrm{NP}_{\mathrm{av} 9} \mathrm{EO}$. Their further research showed that CAPECs were the dominant products of $\mathrm{NP}_{\mathrm{av} 9} \mathrm{EO}$ biotransformation, accounting for $66 \%$ of all metabolites in the effluents of five WWTPs. Additionally, $\mathrm{CA}_{6} \mathrm{PECs}$ and $\mathrm{CA}_{8} \mathrm{PECs}$ were the dominant CAPEC species in WWTP effluents, and $\mathrm{CAP}_{2}$ ECs were approximately twice as abundant as $\mathrm{CAP}_{1} \mathrm{ECs}$ (Di Corcia et al. 2000). Jonkers et al. (2001) found that $\mathrm{CA}_{9} \mathrm{P}_{2} \mathrm{EC}$, $\mathrm{CA}_{5-8} \mathrm{P}_{1} \mathrm{ECs}$, and $\mathrm{CA}_{5-8} \mathrm{P}_{2} \mathrm{ECs}$ were the main products in a laboratory-scale bioreactor filled with $\mathrm{NP}_{\mathrm{av} 9} \mathrm{EO}$-spiked river water. Thus, both environmental survey and our study with isolated bacteria demonstrated that CAPECs were one of the main products of NPEO biotransformation. However, the estrogenic effect of CAPECs remains poorly understood (Montgomery-Brown and Reinhard 2003).

To date, NPEOs degradation experiments using isolated bacteria only confirmed the formation of low-ethoxylated NPEOs $(n=2,3)$ (John and White 1998; Lu et al. 2008), lowethoxylated NPEOs and NPECs ( $n=2$ or 3 ) (Liu et al. 2006; Sato et al. 2001, 2003), or $\mathrm{NP}_{1} \mathrm{EO}, \mathrm{NP}_{1} \mathrm{EC}$, and NP (Liu et al. 2007; Fig. 3a). Thus, the accumulation of CAPECs observed in many laboratory and field studies (Ahel et al. 1994; Di Corcia et al. 1998; Jonkers et al. 2001; Montgomery-Brown et al. 2003, 2008) could not be explained by the above pathways. Using gellan gum as a gelling reagent, we successfully isolated bacteria capable of transforming low-ethoxylated NPEOs to CAPECs. Thus, Fig. $3 \mathrm{~b}$ shows the proposed pathway of $\mathrm{NP}_{\mathrm{av} 2} \mathrm{EO}$ using Variovorax sp. NP427b, Ralstonia sp. NP47a, and Pseudomonas sp. NP522b, and the oxidation of the EO chain and alkyl group to corresponding NPECs and CAPECs. According to Jonkers et al. (2001) and Di Corcia et al. (1998), CAPECs started to accumulate after NPECs were formed during biotransformation of NPEOs. Montgomery-Brown et al. (2008) has found that alkyl chain oxidation of $\mathrm{NP}_{1} \mathrm{EC}$ by microcosms and the formation of $\mathrm{CAP}_{1} \mathrm{ECs}$ is favored under microxic conditions. Thus, it may be possible that pathway 1 is favored by the microxic conditions.

Pathway 2: hydroxyl shift cleavage of $\mathrm{NP}_{\mathrm{av} 2}$ EOs with $\mathrm{NP}_{1} \mathrm{EO}$ as the major degradation product by strain NP42a

(Sphingomonas)

Strain NP42a belonging to the Sphingomonas genus ( $\alpha$ Proteobacteria) degraded $\mathrm{NP}_{\mathrm{av} 2} \mathrm{EO}$ rapidly. As shown in Fig. 5, $\mathrm{NP}_{2} \mathrm{EO}$ and $\mathrm{NP}_{3} \mathrm{EO}$ decreased from 251.7 and $141.7 \mathrm{~mol} \mathrm{~L}^{-1}$ on day 0 to 75.5 and $8.0 \mathrm{~mol} \mathrm{~L}^{-1}$ on day 10 , respectively, while $\mathrm{NP}_{1} \mathrm{EO}$ increased from $156.3 \mathrm{~mol} \mathrm{~L}^{-1}$ on day 0 to $357.6 \mathrm{~mol} \mathrm{~L}^{-1}$ on day 10 . The total concentration of $\mathrm{NP}_{1-3} \mathrm{EO}$ decreased from 549.7 to $441.1 \mathrm{~mol} \mathrm{~L}^{-1}$. NPECs were not formed throughout the whole period, and adsorption by bacterial cells may be responsible for the missing mass. From the above results, it was proposed that biodegradation of the low-ethoxylated NPEOs by NP42a was through the hydroxyl shift cleavage pathway to form $\mathrm{NP}_{1} \mathrm{EO}$, as shown in Fig. 3c. In our previous study, an isolated strain with the same morphological traits and 16S rRNA gene sequence as NP42a degraded $\mathrm{NP}_{\mathrm{av} 9} \mathrm{EO}$ with NP1EO as the major product (Gu et al. 2010). It should be noted, however, that slow

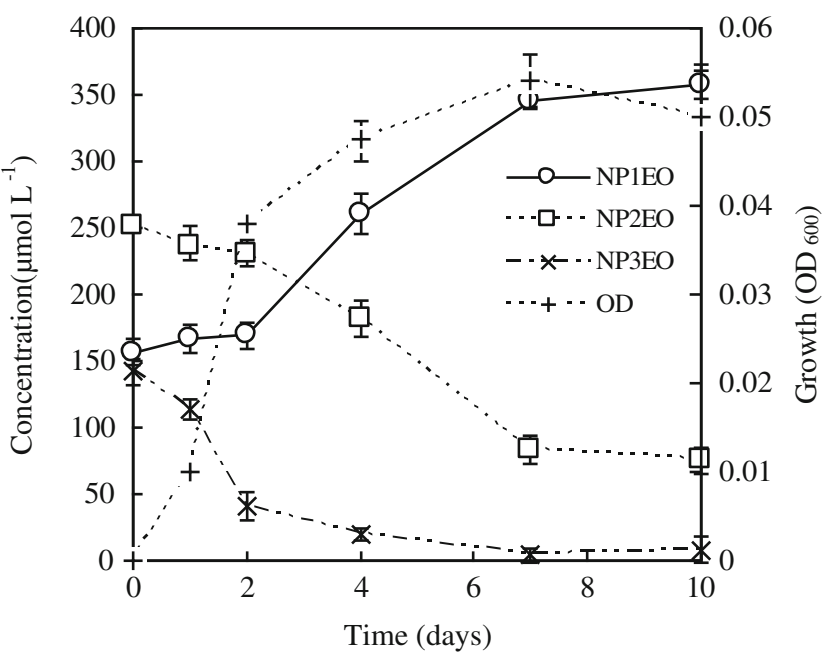

Fig. 5 Changes in concentrations of NPEOs $(n=1-3)$ in the culture media during incubation of strain NP42a. Growth was assessed based on optical density at $600 \mathrm{~nm}$ (OD600) 
mineralization of $\mathrm{NP}_{1} \mathrm{EO}$ might also be possible, which requires further study.

$\mathrm{NP}_{1} \mathrm{EO}$ is regarded as the most toxic and estrogenic NPEO homologue (Metcalfe et al. 2001; Servos 1999) and is widely found in many environments as the main metabolite of NPEOs (Ahel et al. 1994; Ferguson et al. 2001; Kolpin 2002). Few pure strains capable of converting NPEOs to $\mathrm{NP}_{1} \mathrm{EO}$ have been isolated to date. Liu et al. (2006) isolated two strains (Ensifer sp. strain AS08 and Pseudomonas sp. strain AS90) capable of transforming $\mathrm{NP}_{2} \mathrm{EO}$ to $\mathrm{NP}_{1} \mathrm{EO}$, as shown in Fig. 3a. The present study clearly showed that a member of the genus Sphingomonas has the ability to transform lowethoxylated NPEO to $\mathrm{NP}_{1} \mathrm{EO}$ through a nonoxidative pathway. It is known that $\mathrm{NP}_{1} \mathrm{EO}$ has been extensively detected in different environments (Ahel et al. 1994; Ferguson et al. 2001; Kolpin 2002), suggesting that pathway 2 may happen under both anaerobic and aerobic conditions (John and White 1998).

In our previous research, we studied the biotransformation of NPEOs during continuous aerobic treatment of sewage spiked with $23 \mu \mathrm{M}$ technical $\mathrm{NP}_{\mathrm{av} 9} \mathrm{EOs}$ over a period of 90 days (Zhang et al. 2008b), which provided the activated sludge samples for bacterial isolation in the present study. Short-chain NPEOs $\left(\mathrm{N}_{1} \mathrm{PEO}-\mathrm{NP}_{3} \mathrm{EO}\right)(1.62-2.03 \mu \mathrm{mol} / \mathrm{L})$ and NPECs $(2.79-3.30 \mu \mathrm{mol} / \mathrm{L})$ accumulated in the treated effluents. However, CAPECs were not found in the effluent throughout the whole treatment experiment (Zhang et al. 2008b).

\section{Conclusions}

Four low-ethoxylated NPEO-degrading strains belonging to four genera in three classes (Pseudomonas sp. NP522b in $\gamma$ Proteobacteria, Variovorax sp. NP427b and Ralstonia sp. NP47a in $\beta$-Proteobacteria, and Sphingomonas sp. NP42a in $\alpha$-Proteobacteria) were isolated from activated sludge by cultivation with gellan gum as the gelling reagent. This was the first time that degradation of low-ethoxylated NPEOs by strains belonging to Ralstonia and Sphingomonas was observed. A new pathway of the low-ethoxylated NPEOs, i.e., oxidation of low-ethoxylated NPEOs to their corresponding NPECs and CAPECs, was identified using Pseudomonas sp. NP522b, Variovorax sp. NP427b, and Ralstonia sp. NP47a. The nonoxidative pathway with $\mathrm{NP}_{1} \mathrm{EO}$ as the dominant product was confirmed by a new low-ethoxylated NPEOdegrading bacteria, Sphingomonas strain NP42a.

Acknowledgments This work was supported by the major Science and Technology Program for Water Pollution Control and Treatment (2012ZX07313-001-07) and the Ministry of Science and Technology, People's Republic of China (2013DFG50150). We thank Dr. Hideyuki Tamaki and Dr. Yoichi Kamagata for their help on the improved isolation method.

\section{References}

Ahel M, Koch M, Giger W (1994) Behaviour of alkylphenol polyethoxylate surfactants in the aquatic environment-I. Occurrence and transformation in sewage treatment. Water Res 28:11311142

Bergé A, Cladière M, Gasperi J, Coursimault A, Tassin B, Moilleron R (2012a) Meta-analysis of environmental contamination by alkylphenols. Environ Sci Pollut Res 19:3798-3819

Bergé A, Gasperi J, Rocher V, Coursimault A, Moilleron R (2012b) Phthalate and alkylphenol removal within wastewater treatment plants using physicochemical lamellar clarification and biofiltration. Trans of the Wessex Institute. doi:10.2495/WP120311, $12 \mathrm{pp}$

Berryman D, Houde F, Deblois C, O'Shea M (2003) Monitoring of nonylphenol ethoxylates in raw and treated water of eleven drinking water treatment plants in Quebec. Environmental Department, Quebec, Envirodoq: ENV/2003/0001 (in French)

Di Corcia A, Cavallo R, Crescenzi C, Mazzari MA (2000) Occurence and abundance of dicarboxylated metabolites of nonyphenol polyethoxylates surfactants in treated sewages. Environ Sci Technol 34:3914-3919

Di Corcia A, Costantino A, Crescenzi C, Marinoni E, Samperi R (1998) Characterization of recalcitrant intermediates from biotransformation of the branched alkyl side chain of nonylphenol ethoxylate surfactants. Environ Sci Technol 32:2401-2409

Di Gioia D, Michelles A, Pierini M, Bogialli S, Fava F, Barberio C (2008) Selection and characterization of aerobic bacteria capable of degrading commercial mixtures of low-ethoxylated nonylphenols. J Appl Microbiol 104:231-242

Ding WH, Fujita Y, Aeschimann R, Reinhard M (1996) Identification of organic residues in tertiary effluent by GC/EI-MS, GC/CI-MS, and GC/TSQ-MS. J Analyt Ch 354:48-55

EU (2003) Directive 2003/53/CE of the European Parliament and of the Council establishing restrictions on the marketing and use of alkylphenols. Official Journal of the European Union, Luxembourg

Ferguson PL, Iden CR, Brownawell BJ (2001) Distribution and fate of neutral alkylphenol ethoxylate metabolites in a sewage-impacted urban estuary. Environ Sci Technol 35:2428-2435

Gonzalez S, Petrovic M, Barcelo D (2007) Removal of a broad range of surfactants from municipal wastewater- comparison between membrane bioreactor and conventional activated sludge treatment. Chemosphere 67:335-343

Gu X, Zhang Y, Zhang J, Yang M, Tamaku H, Kamagata Y, Li D (2010) Isolation of phylogenetically diverse nonylphenol ethoxylatedegrading bacteria and characterization of their corresponding biotransformation pathways. Chemosphere 80:216-222

Hanada S, Hiraishi A, Shimada K, Matsuura K (1995) Chloroflexus aggregans sp. nov., a filamentous phototrophic bacterium which forms dense cell aggregates by active gliding movement. Int J Syst Bacteriol 45:676-681

He F, Niu LL, Aya O, Wang SL, Wang LG (2013) Occurrence and fate of nonylphenol ethoxylates and their derivatives in Nansi Lake environments, China. Water Environ Res 85:27-34

Isobe T, Nishiyama H, Nakashima A, Takada H (2001) Distribution and behavior of nonylphenol, octylphenol and nonylphenol monoethoxylate in Tokyo metropolitan area: their association with aquatic particles and sedimentary distributions. Environ Sci Technol 35:1041-1049

Jobling S, Sheahan D, Osborne JA, Matthiessen P, Sumpter JP (1996) Inhibition of testicular growth in rainbow trout (Oncorhynchus mykiss) exposed to estrogenic alkylphenolic chemicals. Environ Toxicol Chem 15:194-202

John DM, White GF (1998) Mechanism for biotransformation of nonylphenol polyethoxylates to xenoestrogens in Pseudomonas putida. J Bacteriol 180:4332-4338 
Jonkers N, Knepper TP, De Voogt P (2001) Aerobic biodegradation studies of nonylphenol ethoxylates in river water using liquid chromatography-electrospray tandem mass spectrometry. Environ Sci Technol 35:335-340

Koh YKK, Chiu TY, Boobis AR, Cartmell E, Pollard SJT, Scrimshaw MD, Lester JN (2008) A sensitive and robust method for the determination of alkylphenol polyethoxylates and their carboxylic acids and their transformation in a trickling filter wastewater treatment plant. Chemosphere 73:551-556

Kolpin DW, Furlong ET, Meyer MT, Thurman EM, Zaugg SD, Barber LB, Buxton HT (2002) Pharmaceuticals, hormones, and other organic wastewater contaminants in US streams, 1999-2000: a national reconnaissance. Environ Sci Technol 36:1202-1211

Lane D (1991) 16S/23S rRNA sequencing. In: Stackebrandt E, Goodfellow M (eds) Nucleic acids techniques in bacterial systematics. Wiley, Chichester, pp 115-147

Liu X, Ohta T, Kawabata T, Kawai F (2013) Catalytic mechanism of short ethoxy chain nonylphenol dehydrogenase belonging to a polyethylene glycol dehydrogenase group in the GMC oxidoreductase family. Int J Mol Sci 14:1218-1231

Liu X, Tani A, Kimbara K, Kawai F (2007) Xenoestrogenic short ethoxy chain nonylphenol is oxidized by a flavoprotein alcohol dehydrogenase from Ensifer sp. strain AS08. Appl Microbiol Biotechnol 73:1414-1422

Liu X, Tani A, Kimbara K, Kawai F (2006) Metabolic pathway of xenoestrogenic short ethoxy chain-nonylphenol to nonylphenol by aerobic bacteria, Ensifer sp. strain AS08 and Pseudomonas sp. strain AS90. Appl Microbiol Biotechnol 72:552-559

Lozada M, Figuerola ELM, Itria RF, Erijman L (2006) Replicability of dominant bacterial populations after long-term surfactant-enrichment in lab-scale activated sludge. Environ Microbiol 8:625-638

Lozada M, Itria RF, Figuerola ELM, Babay PA, Gettar RT, de Tullio LA, Erijman L (2004) Bacterial community shifts in nonylphenol polyethoxylates-enriched activated sludge. Water Res 38:2077-2086

Lu J, Jin Q, He Y, Wu J, Zhao J (2008) Biodegradation of nonylphenol ethoxylates by Bacillus sp LY capable of heterotrophic nitrification. FEMS Microbiol Lett 280:28-33

Maguire RJ (1999) Review of the persistence of nonylphenol and nonylphenol ethoxylates in aquatic environments. Water Qual Res J Can 34:37-78

Metcalfe CD, Metcalfe TL, Kiparissis Y, Koenig BG, Khan C, Hughes RJ, Croley TR, March RE, Potter T (2001) Estrogenic potency of chemicals detected in sewage treatment plant effluents as determined by in vivo assays with Japanese medaka (Oryzias latipes). Environ Toxicol Chem 20:297-308

Montgomery-Brown J, Drewes JE, Fox P, Reinhard M (2003) Behavior of alkylphenol polyethoxylates metabolites during soil aquifer treatment. Water Res 37:3672-3681
Montgomery-Brown J, Li YM, Ding WH, Mong GM, Campbell JA, Reinhard M (2008) $\mathrm{NP}_{1} \mathrm{EC}$ degradation pathways under oxic and microxic conditions. Environ Sci Technol 42:6409-6414

Montgomery-Brown J, Reinhard M (2003) Occurrence and behavior of alkylphenol polyethoxylates in the environment. Environ Eng Sci 20:471-486

Nagarnaik PM, Mills MA, Boulanger B (2010) Concentrations and mass loadings of hormones, alkylphenols, and alkylphenol ethoxylates in healthcare facility wastewaters. Chemosphere 78 : 1056-1062

Routledge EJ, Sumpter JP (1996) Estrogenic activity of surfactants and some of their degradation products assessed using a recombinant yeast screen. Environ Toxicol Chem 15:241-248

Salvadori L, Di Gioia D, Fava F, Barberio C (2006) Degradation of lowethoxylated nonylphenols by a Stenotrophomonas strain and development of new phylogenetic probes for Stenotrophomonas spp. Detection. Current Microbiol 52:13-20

Sato H, Shibata A, Wang Y, Yoshikawa H, Tamura H (2001) Characterization of biodegradation intermediates of non-ionic surfactants by matrix-assisted laser desorption/ionization-mass spectrometry 1 . Bacterial biodegradation of octylphenol polyethoxylate under aerobic conditions. Polym Degrad Stab 74:69-75

Sato H, Shibata A, Wang Y, Yoshikawa H, Tamura H (2003) Characterization of biodegradation intermediates of nonionic surfactants by MALDI-MS. 2. Oxidative biodegradation profiles of uniform octylphenol polyethoxylate in O-18-labeled water. Biomacromolecules 4:46-51

Servos MR (1999) Review of the aquatic toxicity, estrogenic responses and bioaccumulation of alkylphenols and alkylphenol polyethoxylates. Water Qual Res J Can 34:123-177

USEPA (2010) Nonylphenol (NP) and nonylphenol ethoxylate (NPEs) action plan. US Environmental Protection Agency, Washington

Xu Y, Luo F, Pal A, Gin KY-H, Reinhard M (2011) Occurrence of emerging organic contaminants in a tropical urban catchment in Singapore. Chemosphere 83:963-969

Ying GG, Williams B, Kookana R (2002) Environmental fate of alkylphenols and alkylphenol ethoxylates a review. Environ Int 28: 215-226

Zhang Y, Sei K, Toyama T, Ike M, Zhang J, Yang M, Kamagata Y (2008a) Changes of catabolic genes and microbial community structures during biodegradation of nonylphenol ethoxylates and nonylphenol in natural water microcosms. Biochem Eng J 39:288-296

Zhang J, Yang M, Qiao Y, Zhang Y, Chen MX (2007) Biodegradation of nonylphenoxy carboxylates mixtures in two microcosms. Sci Total Environ 388:392-397

Zhang J, Yang M, Zhang Y, Chen MX (2008b) Biotransformation of nonylphenol ethoxylates during sewage treatment under anaerobic and aerobic conditions. J Environ Sci 20:135-141 